\title{
Mental distress and demographic, behavioral, obstetric characteristics, and health condition in pregnant women
}

\author{
Betina Harmel, ' Doroteia Aparecida Höfelmann
}

Federal University of Paraná, Postgraduate Program in Collective Health, Curitiba, Paraná, Brazil.

\section{Correspondence:}

Betina Harmel

St: Padre Camargo, 280

Curitiba, PR, 80060-240, Brazil.

Phone: +55 (41) 3360-7271

Email: betinaharmel@gmail.com

Received: 30 November 2020 Accepted: 16 July 2021

\section{Citation:}

Harmel, B., \& Höfelmann, D. A. (2022). Mental distress and demographic, behavioral obstetric characteristics, and health condition in pregnant women. Salud Mental, $45(1), 11-18$.

DOI: $10.17711 /$ SM. $0185-3325.2022 .003$

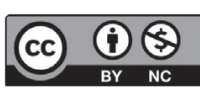

\begin{abstract}
Introduction. Mental distress can have consequences for the health of women and children. Objective. To estimate the prevalence of mental distress and to identify its association with socioeconomic, demographic, health-related behaviors, obstetrics, and health status in pregnant women. Method. Cross-sectional study carried out with women undergoing prenatal care at the Unified Health System in Colombo-Paraná. The prevalence of mental distress was investigated using the Self-Reporting Questionnaire. Results. Among pregnant women $(n=605)$, the prevalence of mental distress was $47.9 \%(95 \% \mathrm{Cl}[44.0,51.9])$. After an adjusted analysis, the following was associated with the outcome: living without a partner (PR 1.27; 95\% $\mathrm{Cl}[1.06$, 1.52]), having up to seven years of schooling (PR 1.30; $95 \% \mathrm{Cl}[1.04,1.63])$, performing moderate or intense physical activity (PR 1.47; 95\% Cl [1.02, 2.12]), consuming alcohol in the last 12 months (PR 1.29; 95\% Cl $[1.08,1.54])$, being in the third pregnancy (PR 1.33; 95\% Cl $[1.06,1.67])$, in the last trimester of pregnancy (PR $1.43 ; 95 \% \mathrm{Cl}[1.06,1.94])$, and the presence of a common pregnancy symptom (PR 1.56; $95 \% \mathrm{Cl}[1.15,2.11]$ ). Discussion and conclusion. Comprehensive mental health care during pregnancy is necessary especially for women in social vulnerability, at the end of pregnancy, and with worse health.
\end{abstract}

Keywords: Pregnancy, mental health, women's health, cross-sectional studies.

\section{RESUMEN}

Introducción. El distrés mental puede afectar la salud de mujeres y niños. Objetivo. Estimar la prevalencia de distrés mental e identificar su asociación con comportamientos socioeconómicos, demográficos, relacionados con la salud, obstetricia y estado de salud en mujeres embarazadas. Método. Estudio transversal realizado con mujeres sometidas a atención prenatal en el Sistema Único de Salud de Colombo-Paraná. La prevalencia del distrés mental se investigó mediante el cuestionario de autoinforme. Resultados. Entre las mujeres embarazadas $(n=605)$ la prevalencia de distrés mental fue de $47.9 \%$ (IC 95\% [44.0, 51.9]). Después del análisis ajustado, lo siguiente se asoció con el resultado: vivir sin pareja (RP 1.27; IC 95\% [1.06, 1.52]), tener hasta siete años de escolaridad (RP 1.30; IC 95\% [1.04, 1.63]), desempeño moderado o actividad física intensa (RP 1.47; IC 95\% [1.02, 2.12]), consumo de alcohol en los últimos 12 meses (RP 1.29; IC 95\% [1.08, 1.54]), estar en el tercer embarazo (RP 1.33; IC 95\% [1.06, 1.67]), en el último trimestre del embarazo (PR 1.43; IC 95\% [1.06, 1.94]) y la presencia de un síntoma común del embarazo (RP 1.56; IC 95\% [1.15, 2.11]). Discusión y conclusión. La atención integral en salud mental durante el embarazo es necesaria especialmente para mujeres en situación de vulnerabilidad social, al final del embarazo y con peor salud.

Palabras clave: Embarazo, salud mental, la salud de la mujer, estudios transversales. 


\section{INTRODUCTION}

Pregnancy is a period marked by significant changes in women's life that go beyond the physiological part, and influence physical, hormonal, and emotional aspects. These changes can have significant repercussions in daily life, and lead to worsening mental health conditions. Sometimes pregnant women have feelings like anguish, fear, and doubt about the future, and they feel more fragile and sensitive (Costa et al., 2010; Alves \& Bezerra, 2020). Problems with mental health during pregnancy, such as depression, can arise from a multifactorial and complex etiology. The dysregulation between the neuroimmune communication network during pregnancy, modifies the maternal environment, thus causing an increase in the appearance of depressive symptoms, as well as unfavourable obstetric outcomes (Leff-Gelman et al., 2016).

During pregnancy, women may have feelings that include anxiety, sadness, discouragement, guilt, and insecurity. These feelings are associated not only with a child's birth, but with other factors, such as the lack of affection and support from both a partner and the family, and concerns about the future (Leite, Rodrigues, de Sousa, de Melo, $\&$ de Melo Fialho, 2014).

The difficulties that arise during this period are often expressed as distress and nuisance, which suggest feelings of discomfort. Nausea and vomiting are frequent during pregnancy, and refer to the etiology of hormonal, biochemical, and physiological changes, as well as psychological factors, which include changes in the emotional aspects of each pregnant woman, in addition to increased responsibility for the birth of a child (Silva \& Silva, 2009; Gonçalves Camacho, da Costa Vargens, Progianti, \& Spíndola, 2010). Althogh several changes occur during pregnancy in the female body in the third trimester depressive symptoms may increase due to body changes, which include swelling of the legs and feet, greater difficulty in breathing and increased tiredness (Gonçalves Camacho et al., 2010). The interactions that occur between external and internal transformations in the body of each pregnant woman emit different feelings, which come about in a particular way (Gonçalves Camacho et al., 2010). Common symptoms may appear, such as alternating between increased and decreased appetite, nausea, vomiting, drowsiness, and tiredness (Sarmento \& Setúbal, 2003; Burti, Andrade, Caromano, \& Ide, 2006).

Maternal mental health may influence a child's health, and ranges from the period of pregnancy up to one year after delivery. The development of a child's health begins long before birth, in early life experiences, which occur in the womb and already influence later development. Conditions related to depression, stress, and anxiety during pregnancy can have negative consequences such as premature birth, low birth weight, increased risk of cognitive and behavioral emotional problems in childhood and adolescence, in addition to depression in adulthood (Lenze, 2017).
Mental distress can be characterized by a set of symptoms sometimes called common mental disorders (CMD) that can not be classifiable by standard diagnostic criteria and involve tiredness, irritability, lack of memory, somatic complaints, insomnia, and difficulty concentrating (Goldberg \& Huxley, 1992; Jebena et al., 2015).

Brazilian studies carried out with pregnant women, who used the Self Reporting Questionnaire (SRQ-20) as a means of tracking mental distress, showed a prevalence between $41.4 \%$ to $57.1 \%$ (Silva et al., 2010; Lucchese et al., 2017). National and international surveys point to a consensus in the literature that low education, low income, being a woman, not having a partner, using controlled medication, and having several children increase the chance of indications for CMD (Lucchese et al., 2017; Guimarães et al., 2019; Furtado, Saldanha, Moleiro, \& Silva, 2019; Gomes, Miguel, \& Miasso, 2013; Senicato, Azevedo, \& Barros, 2018).

Higher income is directly related to better access to economic conditions during life, and the lack or reduction of it often leads to stressful and insecure situations, mechanisms that may trigger CMD (Ludermir \& Melo Filho, 2002). Concerns, doubts about the increase in expenses with the arrival of a child and increasing responsibility for their own support and that of the child tend to increase during the gestational period, and can negatively affect mental health (Leite et al., 2014).

Investigating the factors that contribute to increasing the prevalence of mental distress in more vulnerable social groups, such as pregnant women, is essential. Prenatal care must include all social, anthropological, economic and cultural aspects, while never being restricted to obstetric and clinical actions (Leite et al., 2014). Given the above, the objective of this study was to estimate the prevalence of mental distress and to identify its association with socioeconomic, demographic variables, health-related behaviors, obstetric characteristics and health status in pregnant women attended by the Unified Health System (SUS) in Colombo, Paraná.

\section{METHOD}

\section{Design of the study/description of the sample}

This is a cross-sectional study in a prospective cohort, part of a larger project entitled "Study of life and health conditions during pregnancy and the puerperium," carried out with pregnant women who were undergoing prenatal care at SUS in the city's Basic Health Units of Colombo, Paraná, between March 2018 and September 2019. The study included pregnant women independent of gestational age, previous obstetric outcomes, number of fetus, previous disease, and gestational risk classification.

The study population was estimated based on the number of SisPrenatal (Pregnant Women Monitoring System) 
registrations in $2016(3,807)$. Sample calculations were estimated, considering a $50 \%$ prevalence of the outcome, a margin of error of four percentage points, and a 95\% confidence level, totaling 520 pregnant women to be evaluated. Once added, the percentage of $30 \%$ for losses and refusals in longitudinal studies resulted in 676 pregnant women to be invited to participate in the study. During the consolidation of the fieldwork, incomplete questionnaires were observed for some variables, and in order to increase the power of the study, another $59(11.3 \%)$ more pregnant women were selected to participate in the study $(N=735)$. The estimates were made using the OpenEpi application.

\section{Measurements}

The variables were investigated through a questionnaire composed by the following variables: Demographic: age group (in years, less than or equal to 19, 20 to 29 and 30 or more), self-declared color/race (white and yellow, or black and mixed race), marital status (with partner, without partner), education in years of study $(0-7,8-10,11$, or more). Health-related behaviors: physical activity in which the Physical Activity Questionnaire for Pregnant Women was used in its translated and validated version (Silva, Santana, Lima, Cecchino, \& FD, 2015). This investigates the level of daily physical activity in five dimensions of daily life: household chores and caring for others; paid work, sport/ exercise, commuting and physical inactivity, classified as sedentary, light, moderate and intense; current smoking (yes, no); consumption of alcoholic beverages in the last 12 months (consumed, not consumed); Obstetric: number of pregnancies (one, two, or three), pregnancy planning (yes, no), gestational trimester, divided by weeks $(0-13,14-26$, 27 , or more). Health condition during pregnancy: morbidity (without disease, diagnosed before or during), presence of symptoms since the pregnancy was discovered (yes, no). The diseases and/or health problems were listed: as follows urinary tract infection, diabetes mellitus, systemic arterial hypertension, pre-eclampsia, eclampsia, anemia, and others.

To track mental distress, the Self-Reporting Questionnaire (SRQ-20) was used, recommended by the World Health Organization (WHO) for studies carried out in primary health care. It is considered to be quick, easy to apply, and low cost, composed of 20 dichotomous questions (yes or no), where each affirmative answer is equivalent to one point (Gonçalves, Stein, \& Kapczinski, 2008). The cut-off point used to diagnose mental distress was equal to or greater than seven points, a value similar to other studies carried out with pregnant women (Jebena et al., 2015; Silva et al., 2010; Lucchese et al., 2017; Silva \& Cavalcante Neto, 2015).

\section{Procedure}

The data collection team was composed by trained interviewers, who were undergraduate, had residency, and were master's students at the Federal University of Paraná (UFPR). Quality control was carried out by telephone contact with $11.6 \%(n=64)$ women, which consisted in checking the data reported by the pregnant women at the time of the interviews.

\section{Statistical analysis}

For data entry, a spreadsheet based on a programming language was created. All questionnaires were double typed for conference. The data were analyzed using the Stata 14 Program (STATA Corp. College Station, Texas, USA). Descriptive analyzes were performed by calculating the absolute $(n)$, relative (\%) frequencies and the respective 95\% confidence interval (CI). Prevalence Ratios (PR) were estimated using Poisson Regression with robust adjustment of variance.

Adjusted analyzes of the data were performed, in which the order of the variables considered the hierarchical model presented in Figure 1. Thus, the demographic and socioeconomic variables were first introduced, followed by the health-related, obstetric and health conditions during pregnancy. For the entry of variables in the adjusted model, $p \leq .20$ was considered, and considered significant when $p<.05$. The age group variable was maintained in the model regardless of the $\mathrm{p}$-value in the unadjusted analysis. The fit of the model was verified using the Akaike (AIC) and Bayesian (BIC) information criteria, and the deviance goodness of fit test. To analyze the collinearity between the variables, the variance inflation factor (VIF) was estimated.

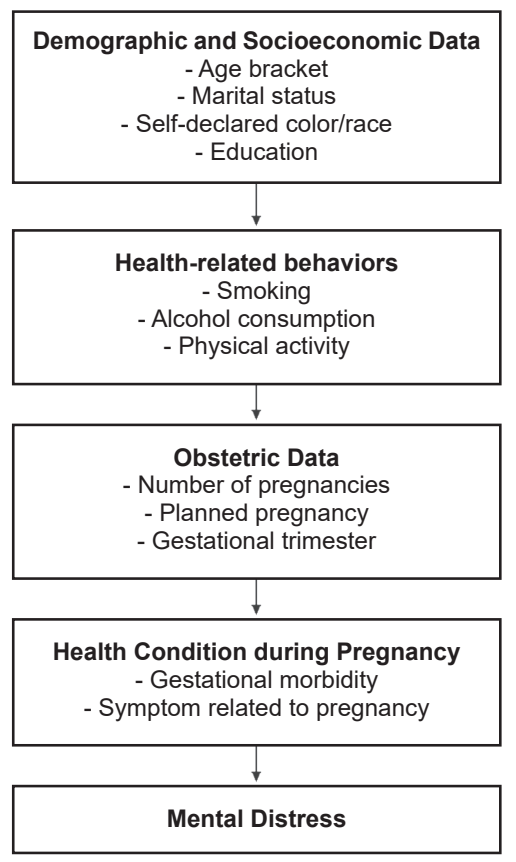

Figure 1. Hierarchical model of multivariable analysis of the association between mental distress and variables in pregnant women during prenatal care at health units in colombo (PR). 2018-2019. 


\section{Ethical considerations}

This research was approved by the UFPR Human Research Ethics Committee under the opinion number 2405347 (11/29/2017). All pregnant women over 18 years old signed the Free and Informed Consent Term (FICT) and those under 18 years old signed the Free and Informed Agreement Term (FIAT) and their legal guardians signed the FICT.

\section{RESULTS}

Seven hundred thirty-five pregnant women were invited to participate in the research, and 605 accepted (82.3\%). The mean age of the pregnant women was 25.9 years $(95 \%$ CI $[25.5,26.4])$, and did not differ from those who refused to participate (26.6 years, 95\% CI [25.7, 27.5]). Most pregnant women lived with a partner (79.7\%) and self-declared their skin color/race as white or yellow (54.2\%); $43.9 \%$ had 11 or more years of study; $44.8 \%$ said they did some kind of light physical activity, $7.6 \%$ were smokers, and $23.8 \%$ reported having consumed alcoholic beverages in the last 12 months.

With regard to obstetric characteristics, $40.9 \%$ were primiparous, $66.2 \%$ did not plan the pregnancy, and $49.8 \%$ were in the third trimester; $71.4 \%$ stated that they had no diagnosed disease. Among those that had one, the most common were: systemic arterial hypertension $(6.6 \%)$, urinary tract infection (6.5\%), and anemia $(5.3 \%) ; 81.3 \%$ reported a common pregnancy symptom: nausea $(66.3 \%)$, heartburn (51.7\%), and vomiting (50.3\%). The prevalence of mental distress was 47.9\% (95\% CI [44.0, 51.9]). (Table 1).

In the unadjusted analysis, the prevalence of mental distress was significantly higher among pregnant women who had no partner (PR 1.32; 95\% CI $[1.10,1.61]$ ), with up to seven years of schooling (PR 1.33; 95\% CI [1.07, 1.67]), who practiced moderate or intense physical activity (PR 1.32; 95\% CI [1.03, 1.70]), smoked (PR 1.35; 95\% CI $[1.07,1.70])$, consumed alcoholic beverages in the last 12 months (PR 1.37; 95\% CI $[1.15,1.63]$ ), were in their third pregnancy (RP $1.31 ; 95 \%$ CI $[1.09,1.58]$ ), in the third trimester of pregnancy (PR 1.34; 95\% CI [1.02, 1.76]), with some disease diagnosed during pregnancy (PR 1.31; 95\% CI $[1.10,1.56])$, and who reported a common symptom during pregnancy (PR 1.48; 95\% CI [1.13, 1.93]). (Table 2).

After the adjusted analysis, it was observed that pregnant women who had no partner (PR 1.27; 95\% CI [1.06, $1.52]$ ), and with less education, with up to seven years of study (PR 1.30 CI 95\% [1,04, 1.63]) remained with a higher prevalence of mental distress. The association between mental distress and physical activity and alcohol consumption in the last 12 months remained significant. Among the obstetric variables, the pregnant women who were in their third pregnancy (PR 1.33; 95\% CI [1.06, 1.67]) and in the third gestational trimester maintained statistical signifi-
Table 1

Distribution of demographic, socioeconomic characteristics, health-related behaviors, obstetric and health conditions during pregnancy and mental distress in pregnant women during prenatal care at health units in colombo (PR). 2018$2019(N=605)$

\begin{tabular}{|c|c|c|}
\hline Variable & $N$ & $\%$ \\
\hline \multicolumn{3}{|c|}{ Demographic and Socioeconomic Data } \\
\hline \multicolumn{3}{|l|}{ Age Bracket (years) } \\
\hline$\leq 19$ & 99 & 16.4 \\
\hline $20-29$ & 377 & 62.3 \\
\hline$\geq 30$ & 129 & 21.3 \\
\hline \multicolumn{3}{|l|}{ Marital Status } \\
\hline Living with a partner & 472 & 79.7 \\
\hline Living without a partner & 120 & 20.3 \\
\hline \multicolumn{3}{|l|}{ Self-declared color/race } \\
\hline White/yellow & 328 & 54.2 \\
\hline Black/mixed race & 277 & 45.8 \\
\hline \multicolumn{3}{|l|}{ Education (years of study) } \\
\hline $0-7$ & 109 & 18.1 \\
\hline $8-10$ & 229 & 38.0 \\
\hline$\geq 11$ & 264 & 43.9 \\
\hline \multicolumn{3}{|l|}{ Health-related behaviors } \\
\hline \multicolumn{3}{|l|}{ Physical Activity } \\
\hline Sedentary & 126 & 20.8 \\
\hline Light & 271 & 44.8 \\
\hline Moderate or intense & 208 & 34.4 \\
\hline \multicolumn{3}{|l|}{ Smoking } \\
\hline Didn't smoke & 546 & 92.4 \\
\hline Smoked & 45 & 7.6 \\
\hline \multicolumn{3}{|c|}{ Alcoholic beverage in the last 12 months } \\
\hline Didn't consume & 410 & 76.2 \\
\hline Consumed & 128 & 23.8 \\
\hline \multicolumn{3}{|l|}{ Obstetric Data } \\
\hline \multicolumn{3}{|l|}{ Number of pregnancies } \\
\hline 1 & 239 & 40.9 \\
\hline 2 & 184 & 31.5 \\
\hline 3 & 161 & 27.6 \\
\hline \multicolumn{3}{|l|}{ Planned pregnancy } \\
\hline No & 394 & 66.2 \\
\hline Yes & 201 & 33.8 \\
\hline \multicolumn{3}{|l|}{ Gestational trimester } \\
\hline $0-13$ weeks & 97 & 16.1 \\
\hline $14-26$ weeks & 206 & 34.1 \\
\hline 27 or more weeks & 301 & 49.8 \\
\hline \multicolumn{3}{|c|}{ Health Condition during Pregnancy } \\
\hline \multicolumn{3}{|l|}{ Gestational morbidity } \\
\hline Without disease & 422 & 71.4 \\
\hline Before pregnancy & 22 & 3.7 \\
\hline During pregnancy & 147 & 24.9 \\
\hline \multicolumn{3}{|c|}{ Symptom related to pregnancy } \\
\hline No & 113 & 18.7 \\
\hline Yes & 492 & 81.3 \\
\hline \multicolumn{3}{|l|}{ Mental Distress } \\
\hline No & 315 & 52.1 \\
\hline Yes & 290 & 47.9 \\
\hline
\end{tabular}


Table 2

Prevalence of mental distress in relation to demographic, socio-economic characteristics, health-related behaviors, obstetrics and health conditions in pregnant women during prenatal care at health units in colombo $(P R) .2018-2019(N=605)$

\begin{tabular}{|c|c|c|c|c|c|c|}
\hline \multirow{2}{*}{$\begin{array}{l}\text { Variable } \\
\text { Demographic and Socioeconomic Data }\end{array}$} & \multicolumn{2}{|c|}{$n(\%)$} & \multirow[t]{2}{*}{ PR $(95 \% \mathrm{Cl})$} & \multirow[t]{2}{*}{$P$-value* } & \multirow[t]{2}{*}{ Adjusted PR } & \multirow[t]{2}{*}{$P$-value } \\
\hline & & & & & & \\
\hline Age Bracket (years) & & & & .212 & & $.505^{\mathrm{a}}$ \\
\hline$\leq 19$ & 54 & $(54.6)$ & 1.00 & & 1.00 & \\
\hline $20-29$ & 177 & $(47.0)$ & $.86(.70 ; 1.06)$ & & $.94(.75 ; 1.17)$ & \\
\hline$\geq 30$ & 59 & $(45.7)$ & $.84(.65 ; 1.09)$ & & $.93(.72 ; 1.22)$ & \\
\hline Marital Status & & & & .002 & & $.010^{\mathrm{a}}$ \\
\hline Living with a partner & 214 & $(45.3)$ & 1.00 & & 1.00 & \\
\hline Living without a partner & 72 & $(60)$ & $1.32(1.11 ; 1.58)$ & & $1.27(1.06 ; 1.52)$ & \\
\hline Self-declared color/race & & & & .598 & & \\
\hline White/yellow & 154 & $(46.9)$ & 1.00 & & & \\
\hline Black/mixed race & 136 & $(49.1)$ & $1.05(.89 ; 1.23)$ & & & \\
\hline Education (years of study) & & & & .004 & & $.009^{a}$ \\
\hline $0-7$ & 60 & $(55.0)$ & $1.33(1.07 ; 1.67)$ & & $1.30(1.04 ; 1.63)$ & \\
\hline $8-10$ & 121 & $(52.8)$ & $1.28(1.06 ; 1.55)$ & & $1.25(1.03 ; 1.52)$ & \\
\hline$\geq 11$ & 109 & $(41.3)$ & 1.00 & & 1.00 & \\
\hline \multicolumn{7}{|l|}{ Health-related behaviors } \\
\hline Physical Activity & & & & .029 & & $.031^{\mathrm{b}}$ \\
\hline Sedentary & 50 & $(39.7)$ & 1.00 & & 1.00 & \\
\hline Light & 131 & $(48.3)$ & $1.22(.95 ; 1.56)$ & & $1.34(.93 ; 1.92)$ & \\
\hline Moderate or intense & 109 & $(52.4)$ & $1.32(1.03 ; 1.70)$ & & $1.47(1.02 ; 2.12)$ & \\
\hline Smoking & & & & .012 & & $.192^{\mathrm{b}}$ \\
\hline Didn't smoke & 261 & $(47.8)$ & 1.00 & & 1.00 & \\
\hline Smoked & 29 & $(64.4)$ & $1.35(1.07 ; 1.70)$ & & $1.20(.91 ; 1.57)$ & \\
\hline Alcoholic beverage in the last 12 months & & & & .001 & & $.004^{\mathrm{b}}$ \\
\hline Didn't consume & 183 & $(44.6)$ & 1.00 & & 1.00 & \\
\hline Consumed & 78 & $(60.9)$ & $1.37(1.15 ; 1.63)$ & & $1.29(1.08 ; 1.54)$ & \\
\hline \multicolumn{7}{|l|}{ Obstetric Data } \\
\hline Number of pregnancies & & & & .011 & & $.021^{c}$ \\
\hline 1 & 110 & $(46)$ & 1.00 & & 1.00 & \\
\hline 2 & 77 & $(41.9)$ & $.91(.73 ; 1.13)$ & & $.95(.75 ; 1.20)$ & \\
\hline 3 & 97 & $(60.3)$ & $1.31(1.09 ; 1.58)$ & & $1.33(1.06 ; 1.67)$ & \\
\hline Planned pregnancy & & & & .058 & & $.182^{\mathrm{c}}$ \\
\hline No & 202 & $(51.3)$ & 1.00 & & 1.00 & \\
\hline Yes & 86 & $(42.8)$ & $.83(.69 ; 1.00)$ & & $.88(.72 ; 1.08)$ & \\
\hline Gestational trimester & & & & .017 & & $.008^{c}$ \\
\hline $0-13$ weeks & 38 & $(39.2)$ & 1.00 & & 1.00 & \\
\hline 14-26 weeks & 93 & $(45.2)$ & $1.15(.86 ; 1.54)$ & & $1.21(.89 ; 1.66)$ & \\
\hline 27 or more weeks & 158 & $(52.5)$ & $1.34(1.02 ; 1.76)$ & & $1.43(1.06 ; 1.94)$ & \\
\hline \multicolumn{7}{|l|}{ Health Condition during Pregnancy } \\
\hline Gestational morbidity & & & & .003 & & $.112^{\mathrm{d}}$ \\
\hline Without disease & 186 & $(44.1)$ & 1.00 & & 1.00 & \\
\hline Before pregnancy & 9 & $(40.9)$ & $.93(.56 ; 1.55)$ & & $.90(.51 ; 1.58)$ & \\
\hline During pregnancy & 85 & $(57.8)$ & $1.31(1.10 ; 1.56)$ & & $1.17(.97 ; 1.40)$ & \\
\hline Symptom related to pregnancy & & & & .004 & & $.004^{\mathrm{d}}$ \\
\hline No & 39 & $(34.5)$ & 1.00 & & 1.00 & \\
\hline Yes & 251 & $(51)$ & $1.48(1.13 ; 1.93)$ & & $1.56(1.15 ; 2.11)$ & \\
\hline
\end{tabular}

Notes: Caption: $\mathrm{PR}=$ Prevalence Ratio, $\mathrm{Cl}=$ Confidence Interval.

* Poisson Regression with robust adjustment of the variance.

a adjusted for socioeconomic and demographic variables; b adjusted for socioeconomic, demographic and health-related behaviors; ${ }^{\mathrm{c}}$ adjusted for socioeconomic and demographic characteristics, health-related and obstetric behaviors; ${ }^{d}$ adjusted for socioeconomic and demographic characteristics, health-related, obstetric and health-related behaviors. 
cance (PR 1.43; 95\% CI [1.06, 1.94]). After adjusting for variables in the other blocks, the reference to a symptom common to pregnancy (PR 1.56; 95\% CI $[1.15,2.11]$ ) remained associated with a higher prevalence of mental distress. The variables smoking, planned pregnancy and gestational morbidity are no longer statistically significant after adjusting for other variables in the model (Table 2).

The AIC and BIC values of the adjusted model were 825.9 and 880.6 , respectively, while the value of the deviance goodness of fit test was 317.9 ( $p$ value $=1,000$ ), indicating good quality of the final model adjustment. The mean value of VIF was 1.11, and ranged from 1.02 for the presence of any symptoms common to pregnancy, to 1.26 for the age group, and 1.37 for the number of pregnancies.

\section{DISCUSSION AND CONCLUSION}

Among the findings of the present study, the high prevalence of mental distress among pregnant women stands out, especially among those who lived without a partner, with less education, who did moderate or intense physical activity, who consumed alcohol in the last 12 months, who were in their gestation, in the last gestational trimestre, and who had some symptoms common to pregnancy.

The prevalence of mental distress among the pregnant women evaluated was $47.9 \%$. In national studies carried out with pregnant women undergoing prenatal care and using the same screening instrument, the prevalence found was $41.4 \%$, in Pelotas in Rio Grande do Sul (Silva et al., 2010) and $57.1 \%$ in a medium-sized municipality in Central Brazil (Lucchese et al., 2017).

The high prevalence of mental distress in the pregnant women in this study can be explained by their low socioeconomic conditions, as well as the suffering caused by the lack of a partner to assist them in the activities and the low level of education, which brings as less years of study contribute to worse socioeconomic condition.

The highest prevalence of mental distress in the women who had no partner was found in other studies (Lucchese et al., 2017; Guimarães et al., 2019; Furtado et al., 2019). In a relationship with good coexistence, individuals share domestic tasks, care for children and financial management, which can mitigate psychological stress (Robles, Slatcher, Trombello, \& McGinn, 2014). Concerns, doubts about the increase in expenses with the arrival of a child and responsibility tend to increase during pregnancy, and can negatively affect mental health (Leite et al., 2014).

The association between low education and mental distress has been previously reported. (Silva et al., 2010; Guimarães et al., 2019; Furtado et al., 2019; Senicato et al., 2018). Higher education brings about a greater capacity to make decisions, cognitive skills, and assertiveness, factors that lead to greater financial independence, control of fer- tility, and care with food, factors directly related to mental health (Senicato et al., 2018).

For pregnant women, the benefits of physical activity include weight gain control, decreased musculoskeletal discomfort, improved cardiovascular system, mood stability, and greater control of gestational hypertension and diabetes mellitus (Melzer, Schutz, Boulvain, \& Kayser, 2010). However, among the pregnant women evaluated in this study, those who were classified as having moderate or intense physical activity had a higher prevalence of mental distress than those who were sedentary. This result was also found by other authors (Silva \& Cavalcante Neto, 2015; Takahasi et al., 2013) who used instruments to measure physical activity that incorporated dimensions of energy expenditure, including daily activities, such as household chores and care for other people. Among the women evaluated, those with mental distress had higher averages for the domains of care for other people and physical inactivity, with no significant differences in the other domains.

Thus, it is possible that most of the activities performed by pregnant women are related to stressful tasks, such as domestic overload, childcare and manual occupational activities, which may be related to a greater mental distress (Silva \& Cavalcante Neto, 2015; Takahasi et al., 2013). Women who have an increase in the burden of domestic work, mainly due to a greater number of children, and who do not receive help in domestic tasks, often reach higher levels of CMD (Araújo, Pinho, \& Almeida, 2005).

Among the women evaluated, those who were in their third pregnancy had a higher prevalence of mental distress. In another study, the average number of children among women with $\mathrm{CMD}$ was 2.9 children $(\mathrm{SD}=1.6)$, and those whithout CMD 2.3 children ( $\mathrm{SD}=1.3$ ) (Parreira et al., 2017). Social, psychological, and emotional demands, such as caring for a newborn or other child at the same time and with low support, can lead to constant concerns and consequently be an important stress factor for women (Almeida, Nunes, Camey, Pinheiro, \& Schmidt, 2012).

Having consumed alcoholic beverages in the last 12 months was also associated with a higher prevalence of mental distress. There are still few studies that address this association in pregnant women. A study in Pelotas, Rio Grande do Sul, carried out with 1,267 pregnant women between 2006 and 2008, found that the prevalence of CMD was higher (58.6\%) in those who consumed alcohol (Silva et al., 2010). Pregnant women who consume more alcohol are more likely to have depressive symptoms, but the reverse association is also possible, in which alcohol consumption is used to alleviate these symptoms (Parreira et al., 2017; Almeida et al., 2012).

Pregnant women who were in the third trimester of pregnancy had a higher prevalence of mental distress. The bodily relationship can play an important role in this result, since it is at the end of the second trimester that the body 
changes become more expressive with an increase in the indisposition caused by the swelling of the legs and feet, increased tiredness and feelings such as body dissatisfaction, low self-esteem, insecurity with physical changes, weight gain, unregulated sleep, pain, discomfort, and hormonal changes that can result in less willingness to do work and daily tasks (Gonçalves Camacho et al., 2010; Piccinini, Lopes, Gomes, \& De Nardi, 2008; Rezende Filho \& Montenegro, 2008).

Pregnant women who reported common pregnancy symptoms, such as nausea, heartburn, and vomiting, had a higher prevalence of mental distress. The high prevalence of the symptoms would be related to the recall period because we asked about the symptoms in the whole pregnancy until we recruited them. Autonomous and hormonal changes during pregnancy can intensify signs and symptoms of psychological distress (Lucchese et al., 2017). Symptoms such as nausea and vomiting can decrease quality of life, have a significant impact on the social life of pregnant women, and interfere with the ability to perform daily and social activities (Kuo, Wang, Tseng, Jian, \& Chou, 2007). Previous studies indicate a relationship between hyperemesis gravidarum and psychological aspects, for example, depressive symptoms and anxiety disorder (Mitchell-Jones et al., 2017; Kjeldgaard, Eberhard-Gran, Benth, \& Vikanes, 2017). The results suggest that the increased risk of developing emotional distress may primarily be a consequence of hyperemesis gravidarum, which can be a cause or effect of mental distress (Mitchell-Jones et al., 2017).

It is noteworthy that the SRQ-20 is a validated questionnaire, recommended for tracking cases of CMD, and should not be used to diagnose mental illness (Gonçalves et al., 2008). The present study has some limitations. As this is a cross-sectional research, it is not possible to offer an opinion about the causal relationship between the variables, such as whether the worst socioeconomic condition led to a higher prevalence of mental distress, or whether having mental distress led to a worse socioeconomic condition. It is also noteworthy that the information was questioned by the interviewer, and there may have been missing answers or an underestimation of the reports.

The sample was also composed only by users who performed prenatal care exclusively at SUS, and this could result in a similarity in the socioeconomic profile. In addition, the challenge of incorporating women who do not perform prenatal care in research that takes place in the health unit environment is recognized. Despite this, the research team was present at different dates and times at the health units, in addition to having collected samples at the Women's Health Unit, while waiting for an ultrasound procedure, which tends to increase the chances of participation of pregnant women.

There was a high prevalence of mental distress among pregnant women, especially among those who lived without a partner, with less education, who practiced moderate or intense physical activity, who consumed alcohol in the last 12 months, were in the third pregnancy, in the third gestational trimester, and who had some symptoms common to pregnancy.

These results highlight the importance of comprehensive health care during pregnancy. The vulnerability and low socioeconomic conditions in the studied public highlight the contribution of this study to society, and the importance of investigating these conditions in vulnerable population, as is the case of pregnant women. Furthermore, few studies have investigated specific aspects of pregnancy in relation to mental distress, such as the presence of symptoms. Pregnancy is a special opportunity to consider mental suffering questions in prenatal care, considering the high prevalence, and potential impact for women and children's outcomes. The presence of pregnant women in primary care during this period opens a window of opportunities for health care that goes beyond the reproductive cycle and reinforces the importance of intersectoral actions in preventing and understanding solutions to mental distress. Future studies can investigate in depth the ways in which mental health is associated with other variables and thus bring benefits to both the health of pregnant women and the children's, as well as for the whole society.

\section{Funding}

This study was partially funded by CAPES Financing code 001 - Master's scholarships for research members; and CNPq scholarships for scientific initiation.

\section{Conflict of interest}

The authors declare they have no conflicts of interest.

\section{REFERENCES}

Almeida, M. S. de, Nunes, M. A., Camey, S., Pinheiro, A. P., \& Schmidt, M. I. (2012). Transtornos mentais em uma amostra de gestantes da rede de atenção básica de saúde no Sul do Brasil. Cadernos de Saúde Pública, 28(2), 385-394. doi: 10.1590/S0102-311X2012000200017

Alves, T. V., \& Bezerra, M. M. M. (2020). Principais alterações fisiológicas e psicológicas durante o Período Gestacional/Main Physiological and Psychological changes during the management period. ID on Line Revistade Psicologia, 14(49), 114-126. doi: 10.14295/idonline.v14i49.2324

Araújo, T. M. de, Pinho, P. de S., \& Almeida, M. M. G. de. (2005). Prevalência de transtornos mentais comuns em mulheres e sua relação com as características sociodemográficas e o trabalho doméstico. Revista Brasileira de Saúde Materno Infantil, 5(3), 337-348. doi: 10.1590/S1519-38292005000300010

Burti, J. S., Andrade, L. Z. de, Caromano, F. A., \& Ide, M. R. (2006). Adaptações fisiológicas do período gestacional. Fisioterapia Brasil, 7(5), 375-380.

Costa, E. S., Pinon, G. M. B., Costa, T. S., de Araújo Santos, R. C., Nóbrega, A. R., \& de Sousa, L. B. (2010). Alterações fisiológicas na percepção de mulheres durante a gestação. Rev Rene Fortaleza, 11(2), 86-93.

Furtado, F. M. de S. F., Saldanha, A. A. W., Moleiro, C. M. M. de M., \& Silva, J. da. (2019). Transtornos Mentais Comunsem Mulheresde Cidades Rurais: prevalência e variáveis correlatas. Saúde e Pesquisa, 12(1), 129-140. doi: 10.17765/2176-9206.2019v12n1p129-140

Goldberg, D. P., \& Huxley, P. (1992). Commom mental disorders: a bio-social model. London: Tavistock. 
Gomes, V. F., Miguel, T. L. B., \& Miasso, A. I. (2013). Common Mental Disorders: socio-demographic and pharmacotherapy profile. Revista Latino-Americana de Enfermagem, 21(6),1203-1211. doi: 10.1590/0104-1169.2990.2355

Gonçalves Camacho, K., da Costa Vargens, O. M., Progianti, J. M., \& Spíndola, T. (2010). Vivenciando repercussões e transformações de uma gestação: perspectivas de gestantes. Ciencia y Enfermería, 16(2), 115-125. doi: 10.4067/ s0717-95532010000200012

Gonçalves, D. M., Stein, A. T., \& Kapczinski, F. (2008). Avaliação de desempenho do Self-Reporting Questionnaire como instrumento de rastreamento psiquiátrico: um estudo comparativo com o Structured Clinical Interview for DSMIV-TR. Cadernos de Saúde Pública, 24(2), 380-390. doi: 10.1590/S0102311 X2008000200017

Guimarães, F. J., Da Silva Santos, F. J., Bern Leite, A. F., De Holanda, V. R., De Sousa, G. S., \& Alburquerque Perrelli, J. G. (2019). Adoecimiento mental en gestantes. Enfermería Global, 18(1), 499-534. doi: 10.6018/eglobal.18.1.328331

Jebena, M. G., Taha, M., Nakajima, M., Lemieux, A., Lemessa, F., Hoffman, R., ... al'Absi, M. (2015). Household food insecurity and mental distress among pregnant women in Southwestern Ethiopia: a cross sectional study design. BMC Pregnancy and Childbirth, 15(1), 1-9. doi: 10.1186/s12884-015-0699-5

Kjeldgaard, H. K., Eberhard-Gran, M., Benth, J. Š., \& Vikanes, Å. V. (2017). Hyperemesis gravidarum and the risk of emotional distress during and after pregnancy. Archives of Women's Mental Health, 20(6), 747-756. doi: 10.1007/ s00737-017-0770-5

Kuo, S.-H., Wang, R.-H., Tseng, H.-C., Jian, S.-Y., \& Chou, F.-H. (2007). A comparison of different severities of nausea and vomiting during pregnancy relative to stress, social support, and maternal adaptation. Journal of Midwifery \& Women's Health, 52(1), e1-e7. doi: 10.1016/j.jmwh.2006.10.002

Leff-Gelman, P., Mancilla-Herrera, I., Flores-Ramos, M., Cruz-Fuentes, C., ReyesGrajeda, J. P., García-Cuétara, M. del P., ... Pulido-Ascencio, D. E. (2016). The immune system and the role of inflammation in perinatal depression. Neuroscience Bulletin, 32(4), 398-420. doi: 10.1007/s12264-016-0048-3

Leite, M. G., Rodrigues, D. P., de Sousa, A. A. S., de Melo, L. P. T., \& de Melo Fialho, A. V. (2014). Sentimentos advindos da maternidade: revelações de um grupo de gestantes. Psicologia em Estudo, 19(1), 115-124. doi: 10.1590/14137372189590011

Lenze, S. N. (2017). Early childhood mental health: starting early with the pregnant mother. Child and Adolescent Psychiatric Clinics of North America, 26(3), 411426. doi: 10.1016/j.chc.2017.02.001

Lucchese, R., Simões, N. D., Monteiro, L. H. B., Vera, I., Fernandes, I. L., Castro, P. A. de, ... Lemos, M. F. (2017). Fatores associadosà probabilidade de transtorno mental comumem gestante: estudo transversal. Escola Anna Nery, 21(3), e20160094. doi: 10.1590/2177-9465-EAN-2016-0094

Ludermir, A. B., \& de Melo Filho, D. A. (2002). Condições de vida e estrutura ocupacional associadas a transtornos mentais comuns. Revista de Saúde Pública, 36(2), 213-221. doi: 10.1590/S0034-89102002000200014

Melzer, K., Schutz, Y., Boulvain, M., \& Kayser, B. (2010). Physical Activity and Pregnancy: Cardiovascular Adaptations, Recommendations and Pregnancy
Outcomes. Sports Medicine, 40(6), 493-507. doi: 10.2165/11532290000000000-00000

Mitchell-Jones, N., Gallos, I., Farren, J., Tobias, A., Bottomley, C., \& Bourne, T. (2017). Psychological morbidity associated with hyperemesis gravidarum: a systematic review and meta-analysis. BJOG: An International Journal of Obstetrics \& Gynaecology, 124(1), 20-30. doi: 10.1111/1471-0528.14180

Parreira, B. D. M., Goulart, B. F., Haas, V. J., Silva, S. R. da, Monteiro, J. C. dos S., \& Gomes-Sponholz, F. A. (2017). Transtorno mental comum e fatores associados: estudocom mulheres de uma área rural. Revista da Escola de Enfermagem da USP, 51, e03225. doi: 10.1590/s1980-220x2016033103225

Piccinini, C. A., Lopes, R. S., Gomes, A. G., \& De Nardi, T. (2008). Pregnancy and motherhood. Psicologia em Estudo, 13(1), 63-72. doi: 10.1590/S141373722008000100008

Rezende Filho, J. D., \& Montenegro, C. A. B. (2008). Obstetrícia Fundamental (11 Ed.). Rio de Janeiro: Guanabara Koogan.

Robles, T. F., Slatcher, R. B., Trombello, J. M., \& McGinn, M. M. (2014). Marital quality and health: A meta-analytic review. Psychological Bulletin, 140(1), 140187. doi: $10.1037 / \mathrm{a} 0031859$

Sarmento, R., \& Setúbal, M. S. V. (2003). Abordagem psicológica em obstetríca: aspectos emocionais da gravidez, parto e puerpério. Revista de Ciências Médicas, 12(3), 261-268.

Senicato, C., Azevedo, R. C. S. de, \& Barros, M. B. de A. (2018). Transtorno mental comum em mulheres adultas: identificando os segmentos mais vulneráveis. Ciência \& Saúde Coletiva, 23(8), 2543-2554. doi: 10.1590/141381232018238.13652016

Silva, F. T., Santana, E. F., Lima, J. W., Cecchino, G. N., \& FD, S. C. (2015). Translation and cross-cultural adaptation of the Pregnancy Physical Activity Questionnaire (PPAQ) to the Brazilian population. Ceska gynekologie, 80(4), 290-298.

Silva, K. G. M. da, \& Cavalcante Neto, J. L. (2015). Fatores associados ao transtorno mental comum e níveis de atividade física em gestantes. Revista Brasileira de Ciência e Movimento, 23(2),113-122. doi: 10.18511/0103-1716/rbcm. v23n2p113-122

Silva, L. J. da, \& Silva, L. R. da. (2009). Mudanças na vida e no corpo: vivências diante da gravidez na perspectiva afetiva dos pais. Escola Anna Nery, 13(2), 393-401. doi: 10.1590/S1414-81452009000200022

Silva, R. A. da, Ores, L. da C., Mondin, T. C., Rizzo, R. N., Moraes, I. G. da S., Jansen, K., \& Pinheiro, R. T. (2010). Transtornos mentais comuns e auto-estima na gestação: prevalência e fatores associados. Cadernos de Saúde Pública, 26(9), 1832-1838. doi: 10.1590/S0102-311X2010000900016

Takahasi, E. H. M., Alves, M. T. S. S. de B., Alves, G. S., Silva, A. A. M. da, Batista, R. F. L., Simões, V. M. F., ... Barbieri, M. A. (2013). Mental health and physical inactivity during pregnancy: a cross-sectional study nested in the BRISA cohor study. Cadernos de Saúde Pública, 29(8), 1583-1594. doi: 10.1590/0102$311 \mathrm{X} 00115112$ 